\title{
Theory, research, clinical practice and training: a virtuous circle through Social Cognitive Transactional Analysis
}

\author{
C2012 Carla de Nitto, TSTA-Psychotherapy, Susanna Bianchini, TSTA- \\ Psychotherapy, Maria Teresa Tosi, TSTA-Psychotherapy
}

\begin{abstract}
This presentation describes our view of research, strictly linked to clinical practice, in creating theoretical constructs, forming a virtuous circle within our training model, putting together quantitative and qualitative research. We consider our contribution as a meta-level reflection on research.

The Experiential Learning Model of Kolb and Fry (1975) will be used to explain the circular relation between research, theory, clinical practice and training. The authors state that learning, change and growth empower each other through a circular process based on four different aspects: Concrete Experience, Reflective Observation, Abstract Conceptualization and Active Experimentation. We will describe how these elements impact on the different activities that are part of this virtuous circle.
\end{abstract}

\section{Introduction}

Our presentation aims to underline the value of the circular relationship between theory, research, clinical practice and training, to show how this virtuous circle works and its implications in our training model, starting from the SCTA perspective.

We assume that theory, research, clinical practice and training are four elements that influence each other in a circular way: theoretical knowledge helps to recognize some clinical phenomena and to orient the process of hypothesis construction in order to explain clinical phenomena. On the other hand, hypothesis guides clinical intervention and its result, looking at its efficacy, helps to confirm or not the hypothesis. If the hypothesis is confirmed, we may assume that an aspect of the theory is shaped on the phenomenon we were addressing; if it is not confirmed, we need to look for a new theoretical explanation. Generally, the observation of the relationship among the components of the phenomenon supports the creation of new hypotheses which need to be validated through the clinical research; if the research confirms a new hypothesis, a new theoretical construct is built and consequently influences clinical methodology. This interdependence among theory, research and clinical practice informs the training model which is focused on training competent psychotherapists able to promote intrapsychic and interpersonal wellbeing. This circularity influences our training, as we will show through our presentation and through an example at the end.

We ground our perspective on the basic assumptions of the experimental method applied to the study of human phenomena, considering the complexity of this special object of study. Considering the two different perspectives of the science looking at the phenomena, the nomothetic and the idiographic perspective, we will demonstrate how to combine them looking at the person through these different glasses. We also ground our training on the Experiential Learning circular model of Kolb and Fry (1975). The description of their model will allow description of the relevant and basic elements that guide our learning philosophy which founds our training model.

In conclusion, we will show the virtuous circle in action, using the concept of Ego State in the Social Cognitive Transactional Analysis perspective, through an example in a supervision setting.

One of our goals for the future is to support theoretical reflections presented in this context with an empirical research, using quantitative and qualitative methods.

\section{Science and the nomothetic and idiographic conception}

Science offers two different ways of looking at the people, the nomothetic conception, that looks at similarities between people, and the idiographic conception, that looks at differences between them. This kind of distinction implies different theoretical 
views and practical approaches, that need to be clarified before going on, so that we might look at the richness of each of them and create a possible functional synthesis between these conceptual views.

Which kind of resources and limits can each of them offer? We will start by considering the nature of this distinction, looking at the implications for the research, clinical practice and training.

We may state that the nomothetic approach, looking at the similarities between people, allows us to generalize the results coming from a sample to a large group. Those who use the nomothetic approach seek to describe people using a reduced number of general features from which to derive other specific features. For example, in an interpersonal model the researcher may choose to describe all the interpersonal activities as based on three dimensions: affection, interdependence and self-other relationship (Benjamin, 1974) and look at the interpersonal activities from these three dimensions.

Observing the configurations of the qualities found from this perspective, he can derive categorical conceptualizations or personality styles.

The nomothetic conception is clearly represented in scientific naturalism; scientific naturalism mainly studies the observable phenomena, which are "analyzable" in order to gather generalized conclusions. This goal can be achieved through the rigor and stringency of quantitative research. In training and in clinical practice it offers a guide starting from general conclusions that can be applied and gives some structure and a possible path to follow and can be especially useful in the first stages of training/supervision (Erskine, 1982)

This kind of approach is reductive because it does not take into account the subjective experience of the person, his/her willingness, intentionality and freedom. This implies that is not possible to keep the uniqueness and individuality of the human person.

The idiographic approach illuminates the shadows left by the nomothetic approach. The idiographic approach is strongly grounded on the hermeneutics that allow us to study the construction of the meanings of the specific person. Qualitative research is a proper instrument to the study of a "single case": looking at the personal historical life of the person we can discover how some script decisions are the best way to manage the world and to survive in the relational network.

The idiographic conception allows us to keep the richness of the person's biographical history but cannot justify how to generalize to others the knowledge coming from the individual.

From this overview each of these conceptions of the science can be considered as a thorn in the side of the other. Scilligo (2009) handles this dilemma between the advantages/disadvantages of each of them by proposing to distinguish the methodological level from the epistemological one. From this distinction we derive the possibility to use an idiographic epistemology supported by the nomothetic and idiographic methodology. In synthesis, we state the importance of approaching the study of the human person from a perspective that implies the constant dance between the objective and subjective perspective, the quantitative and qualitative dimensions of the research, the data analysis and the hermeneutics.

In our training, the experiential learning theory of Kolb and Fry (1975) allows a combination of the strengths and limits of the two conceptions of the science, the nomothetic and idiographic ones.

\section{The Experiential Learning Theory}

Our training model is strongly grounded on the dance among theory, research, clinical practice and the Experiential Learning Theory (Kolb and Fry, 1975) guides us to combine these three didactic moments.

The Experiential Learning Theory furnishes a wide model taking into account the high level of complexity implied in the learning process. It identifies four basic learning styles, four learning modes and four learning environments that we will describe in synthesis below.

The four learning styles are named Accommodative, Assimilative, Divergent, and Convergent. The learning styles are based on four different modes: Concrete Experience, Reflective Observation, Abstract Conceptualization and Active Experimentation. Four different learning environments are most conducive for accommodating the different learning styles and learning modes. They are the Affective learning environment, the Symbolic learning environment, the Perceptual learning environment, and the Behavioural learning environment.

We start by describing the relationship among the learning styles, the learning modes and the specific learning environment supportive for each learning style. Because certain learning modes are incorporated within more than one learning style, we will start defining the four modes and then the four learning styles and the four learning environments. At the end, we will explain how we take into account the relationship among learning styles, learning modes, and learning environments in our training model.

\section{Learning modes}

Learning through Concrete Experiences(CE) is typical for people who prefer to feel and experience rather than think. Kolb describes them as intuitive decision makers, who value circumstances involving people in real world situations. This learning mode is "...concern[ed] with the uniqueness and complexity of present reality as opposed to theories and generalizations" (Kolb, 1984, p. 68). More often than not, people who prefer the concrete experience learning mode take an artisticintuitive approach to problem solving rather than an objective approach.

The Reflective Observation (RO) mode focuses on the ability to understand the meaning of ideas. Individuals who are characterized by this mode value objective 
judgment, impartiality, and patience. They prefer abstract understanding to practical applications, and to reflect and observe rather than act on a situation.

The Abstract Conceptualization (AC) mode is typical for individuals oriented toward abstract level of understanding and involved in tasks that require logical investigation of ideas and concepts. Unlike concrete experiences, this learning mode is characterized by a preference to depend on cognitive rather than emotional skills. Commonly, individuals who prefer this mode involve themselves with problems that require the ability to build general theories in order to come up with a solution. They are competent in following tasks that imply "systematic planning, manipulation of abstract symbols, and quantitative analysis" (Kolb, 1984, p. 69).

Finally the Active Experimentation (AE) learning mode focuses "on actively influencing people and changing situations" (Kolb, 1984, p. 69). In other words, individuals in this learning mode prefer to be involved in peer interactions that allow them to play an integral role in the decisions made in these interactions. This mode amplifies practical applications or solutions rather than reflective understanding of a problem. People who use this mode are more focused on doing rather than observing, they are motivated to manage, to manipulate their environments in order to produce the attended results.

It is important to underline that some combination of these learning modes are incorporated within the four Learning Styles shown in Figure 1.

\section{Learning styles}

The Assimilative learning style is characterized by the ability to reason inductively. People who prefer this learning style are competent to "create theoretical models in assimilating disparate observations into an integrated explanation" (Kolb, 1984, p.78).

Assimilators concern themselves with ideas and abstract concepts rather than with people and social interactions and are concerned with abstract, logical rather than practical aspects of theories. Individuals who use the assimilative style incorporate the learning modes of Reflective Observation and Abstract Conceptualization.

The Accommodative learning style is opposed to the assimilative style because people who prefer this learning style excel at accomplishing tasks by following directions, meticulously planning, and ultimately seeking new experiences (Kolb, 1984). They have the ability to adapt themselves to changing circumstances. Unlike assimilative learners, those who are accommodative

\section{Figure 1: Conceptual Schematic of Kolb's Learning Styles, Modes, and respective Learning}

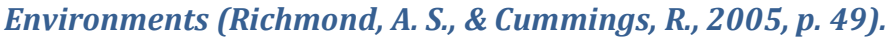
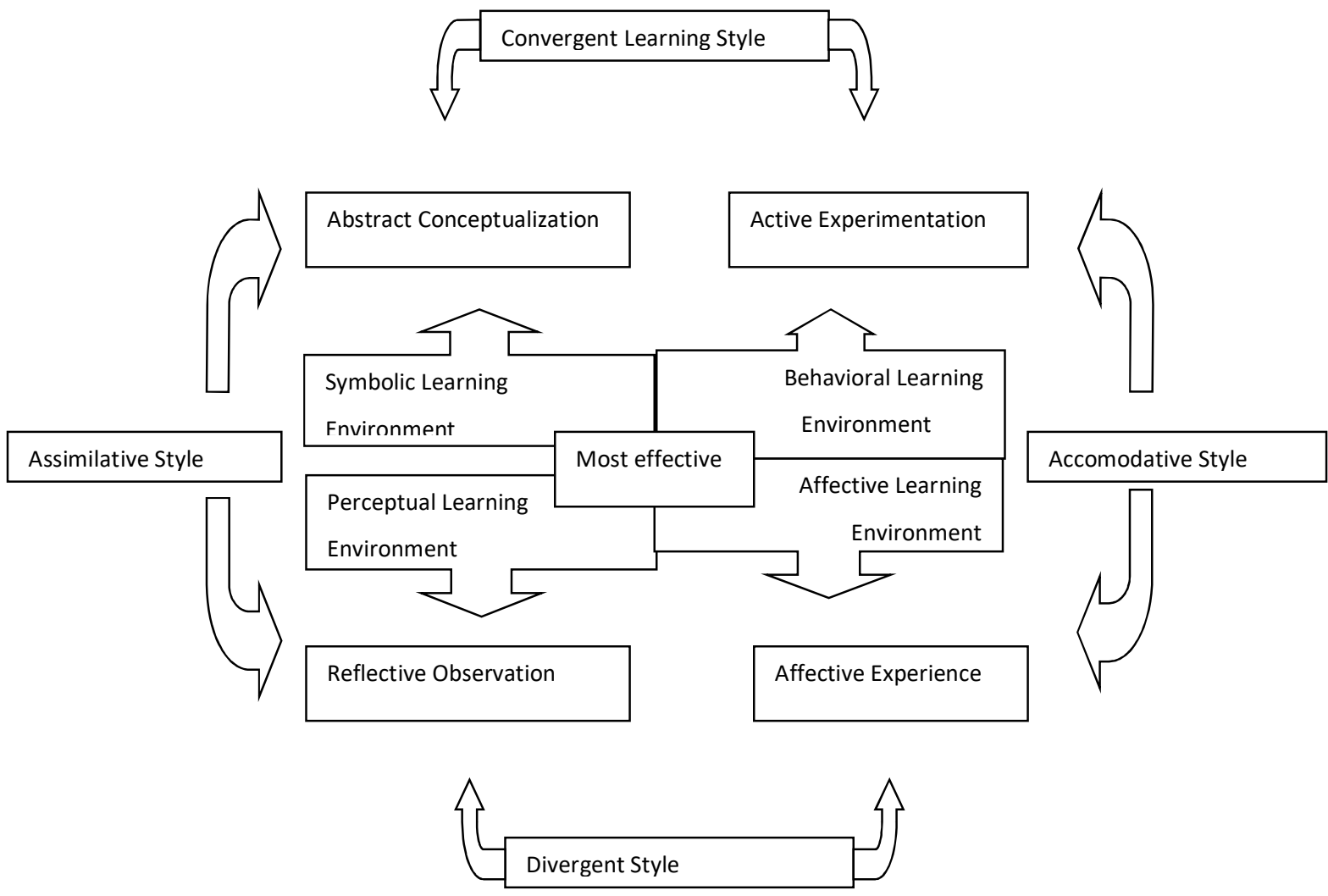
solve problems in an intuitive trial-and-error manner rather than through careful examination of facts, and they rely heavily on other people for information rather than on their own analytic ability. For this reason, the learning modes associated with accommodative learners include Concrete Experience and Active Experimentation.

The Convergent learning style is characterized by the ability to efficiently solve problems, make decisions and apply practical ideas to solve problems. Generally, people who prefer this style can organize knowledge by hypothetical deductive reasoning and for this reason they are able to converge on an operational decision. Hudson (1966) suggests that people with this learning style prefer dealing with technical tasks and problems rather than with issues that involve interpersonal and social interactions.

The relational problems have more elements of unpredictability and complexity that sometimes cannot be resolved with choices based only on the operational logical-deductive reason. Convergent learners draw from the learning modes of Abstract Conceptualization and Active Experimentation.

The Divergent learning style is particularly suitable to manage tasks that require "imaginative ability and awareness of meaning and value" (Kolb, 1984, p. 77). Individuals with this learning style have the ability to look at concrete examples to identify the same concept; this means that the same concept is recognized from many perspectives. In this way they are competent to generate numerous qualities about this concept and are able to organize these qualities by how each quality interrelates to others. The result consists of a meaningful "gestalt" whole of the concept. They are considered "brainstormers"(ib., p. 77), prefer to observe rather than act, are emotionally-oriented and tend to be very creative. Divergent learners prefer the learning modes of Concrete Experiences and Reflective Observation.

\section{Learning environments}

According to Kolb (1984), there are four learning environments that support the various learning styles and their associated modes. These include the Affective, Symbolic, Perceptual, and Behavioural learning environments.

The Affective learning environment enhances concrete experiences so that students actually experience what it might be like to be a professional in a given field of study.

In psychotherapy training, affective learning tasks include activities such as practical exercises and roleplay field experiences. Information is usually peer oriented and delivered informally. The teacher is considered as a role model and an exemplar for the particular field of study. Activities are non-competitive, and feedback should not be comparative but personalized to the individual student's goals and needs (Kolb, 1984).
The Symbolic learning environment is one in which learners are involved in trying to solve problems for which there is usually a right answer or a best solution. Information is abstract and usually presented in readings, data, pictures, and lecture formats.

Characteristic activities may include lecture, homework, and theory readings. The instructor is acknowledged as the expert, enforcer of rules, regulator of time, and taskmaster. This instructional format is typically didactic with a top-down, hierarchical class structure (Kolb, 1984).

The Perceptual learning environment is one in which the main goal is to identify and understand relationships among concepts. Unlike activities in the symbolic environment, the perceptual environment emphasizes the process of problem solving rather than coming up with the best solution. Learners are required to collect relevant information for researching questions and are expected to observe a problem situation through different perspectives.

In this environment, the teacher's role is to act as a facilitator of the learning process, to not be evaluative, and to act as mirror by reflecting back student observations and comments. Learning processes may include reflective exercises such as search for explanatory hypotheses of the client's problem from different theoretical perspectives.

Finally, the Behavioural learning environment emphasizes actively applying knowledge or skills to a practical problem. In this environment learning is encouraged through structured feedback (votes, reviews) that may be a reinforcement of the demonstrated competence.

Small group work, interactive projects that apply theory to real-problem settings, and peer feedback are prime examples of student activities in this environment.

In summary, to accommodate all types of learning styles, we should consider how to incorporate each learning environment suggested by Kolb and Fry (1975). Figure 1 depicts a conceptual framework of the four learning styles, learning modes, and learning environments.

\section{The model of Kolb and Fry in action}

Kolb and Fry (1975) state that each of the four learning environments is supportive of a particular learning mode with its accompanying learning styles.

This means that it is possible to structure a specific environment applying the learning modes and related styles that we are addressing in order to take into account different moments of the learning process and different styles of the trainees.

Specifically, the Symbolic Learning Environment mainly supports the Abstract Conceptualization learning mode, which is part of both the Convergent learning style and the Assimilative learning style.

The Perceptual Learning Environment is the most effective environment for the Reflective Observation 
learning mode that is part of the Divergent and Assimilative learning styles.

The Behavioural Learning Environment best supports the Active Experimentation learning mode, which is part of the Convergent and Accommodative learning styles.

Finally, the Affective Learning Environment is the most effective learning environment for the Concrete Experiences learning mode, which is part of the Divergent and Accommodative learning styles (Kolb, 1984).

\section{Experiential Learning Model and nomothetic} and idiographic approach

According to the Experiential Learning theory and the above mentioned two conceptions of the science, we may consider how different styles fit to the different approach.

We assume that looking at the different learning styles and at their definitions, Convergent and Assimilative ones are mainly typical of the nomothetic approach; they imply the ability to use data analysis and theoretical constructs as glasses to approach reality. People who prefer this style look at possible links between data and specific theoretical constructs. They explore the situation in order to look for the similarities between people in order to come to generalized conclusions and to find the way to intervene in a specific situation through pattern yet validated by theory, research and previous learning; for example, they apply techniques according to specific structured modalities founded on theoretical grounds.

Accommodative and Divergent learning styles are mainly involved with the idiographic approach. People with these prefered styles privilege creative thinking and hermeneutics in order to create co-constructed meaning with the person, instead of referring to rigorous constraints of facts and theories.

Both of these approaches help to look at the reality from a proper perspective; the possibility to take advantage from each of them enhances the efficacy of the learning process.

We recognise; in overall view, the basis of the experimental method, which combines the data observation with the creation of hypotheses strongly anchored to theoretical constructs that need to be verified in practice with operational definitions in order to come to general conclusions that offer a map to effectively intervene in a specific situation.

In synthesis, this perspective informs, from one hand, the qualitative and quantitative research, and, from the other, our training model with methodological implications.

\section{Application to our training model}

We will show how we apply this frame of reference to train future Psychotherapists and Transactional Analysts.
First of all we consider the richness in training groups: different learning environments facilitate the learning process of people that use different styles to learn. Different environments contribute to enlarge students' personal modes looking from different glasses that are more familiar for different people in the training group. Modelling, so considered in Social Learning theory (Bandura, 2012; 2002) strongly supports the learning process in group.

Different moments of the training program can be considered as Learning environments, strongly linked to Learning modes, in order to reach different Learning styles.

Figure 2 synthetically shows the combination of different modes in different moments of the training.

Our training model is organised in many different activities that address different modes, as we will describe below: experiential personal work in group, teaching, practical exercises on specific theoretical units, supervision, in different settings according to the progressive competence of trainees in different years of training: live supervision (starting from the second part of the first year) audio supervision based on the experiential work/therapy- in peer group of four trainees, in the second year of training and on the therapy with the client, starting from the third year; finally, case supervision, starting from the third year aimed at planning treatment consistently to case formulation - with the support of tapes and transcription), brief therapy with the client, with the presence of another trainee as Observer.

Because of the complexity of the process and the copresence of many levels in each of these activities, which imply different environments, more than one mode is contemporaneously present (Figure 2 ).

In the therapeutic setting one of the trainees is personally involved in the activity - Active Experimentation - while the rest of the group observes the process - Reflective Observation - and may be stimulated after each work to analyze it in terms of Abstract Conceptualization.

In the teaching setting Abstract Conceptualization dominates even if is strongly linked with clinical exemplifications that imply Concrete Experience, if trainees are personally involved in it.

During the practical exercises on specific theoretical units Active Experimentation and Concrete Experience are mainly involved, while trainees apply theoretical constructs - Abstract Conceptualization and for the observer Reflective Observations.

During the live supervision, two trainees are directly involved, one as therapist - Active Experimentation and one as client - Concrete Experience. The rest of the group, often with specific observation tasks, is stimulated to Reflective Observation and to Abstract Conceptualization. Very often, in addition, some trainee is also personally touched - Concrete Experience. 
The audio supervision, on tapes, and the case supervision, involves all modes, especially considering the group setting. Concrete Experience and Active Experimentation are involved in the process of presenting the case/contract/treatment planning; at the same time the material is usually organized taking into account theoretical concepts (Abstract Conceptualization) and strongly anchored to data (Reflective Observation).

Finally, brief therapy with the client, with the presence of another trainee as Observer furnishes a wonderful opportunity to use all modes in different moments. The therapist is involved in Concrete Experience and in Active Experimentation while the Observer is in Reflective Observation, and often is also emotionally involved, implying also Concrete Experience. After each session, both together reflect on data and on their experience, connect it to all the processes and the treatment plan and fill a schedule where they synthesize the session especially at a processual level, taking into account a grid for supervision (de Nitto, 1990, 2006).

From this perspective each activity stimulates, at the beginning, a learning environment (symbolic or perceptual or affective or behavioural) and allows the start of a circular learning process in which each student can put forward his learning style (assimilative, convergent, accommodative, divergent) and learn from peers.

\section{An example in supervision}

We present a didactic moment, choosing to pay attention, specifically, to the four learning modes (Reflective Observation, Concrete Experience, Active Experimentation and Abstract Conceptualization). Our goal is to show how the four learning modes are involved in learning activities and promote a cyclic model of learning.

In a live supervision setting, in the third year of training, one of the trainees, a woman, starts a 20 minutes session, verbally complaining about her sense of isolation; she does not like it and wishes to be part of the group, starting from sharing with the group her difficulty, instead of remaining isolated.

The therapist accepts the contract and starts to explore the problem, looking at possible hypotheses in order to choose specific interventions to work on the contract. She looks at the data in order to understand the process and to identify a possible theoretical concept to conceptualize the problem of the client (Reflective Observation and Abstract Conceptualization).

During the supervision process, after the work, she explains that she was immediately aware of the discrepancy between the verbal language and the nonverbal one, starting from the Reflective Observation. So she decides to explore it. She also notices that the client was talking, sitting in a corner, very slowly and softly so that is difficult to listen to her. She also covers her mouth with her hands so that is not possible to read her lips. She seems to be centred on herself and seems not aware of the impact of her behaviour on the others
(Concrete Experience) while the other members of the group are silently watching her.

The therapist speculates (Abstract Conceptualization) that she remains in an internal dialog rather than in an interpersonal process and chooses to invite her to notice her voice, her attitude and to look outside, to others, in order to invite her to enlarge her own perspective (stimulating Concrete Experience). The client accepts the invitation and opens her shoulders and starts to look at the other people in the group. She continues her work going back and forth between feeling isolated and feeling inside the group, especially when she starts to become aware of the attitude of her colleagues: she is so surprised that they warmly look at her. Through some questions from the therapist, the client realizes that she often isolates herself when she is in a group and chooses to pay attention to this issue.

This example shows the excellent opportunity to stimulate learning in the group context through the cyclic model of learning. Each of the participants, including the client, can communicate how they felt when the client complained and when she accepted the therapist's invitation. Through the Concrete Experience based on self-contact, they can learn something about the issue of isolation in a group context. The participants can also learn by reflecting on the colleague's experience from different perspectives; for example, through behavioural diagnosis looking at verbal and non-verbal signs of the client and so they discover the activation of some ego state. Doing so, they can recognize some theoretical aspect (Abstract Conceptualization) starting from the Reflective Observation.

They can also look at the same situation from different perspectives, guided by specific tasks, so that the supervision process would help them to systematically integrate observations into a coherent theory; for example, the theory of racket system. They may ask the therapist what kind of hypothesis she built about the client's ego state and why she chooses to pay attention to the client's non-verbal language and the therapist can explain what decision she took after the hypothesis and in so doing she is modelling how to learn through Active Experimentation.

\section{Research, training, clinical practice and theory: a virtuous circle through Social Cognitive Transactional Analysis}

Social Cognitive Transactional Analysis (Scilligo, 2009) proposes a concept of ego state that helps to see the virtuous circle between research, training, clinical practice and theory in action.

Pio Scilligo started his definition of Ego state from a theoretical approach; in continuity of the Bernian conception (De Luca, Tosi, 2012; Tosi, de Nitto, Bianchini, 2012), he created his definition of Ego state, looking at the theory of relational schemata (Baldwin, $1992,1994,1997)$, at the theory of relational self (Andersen \& Chen, 2002), at the theory of Distributed Parallel Process (Rumelhart \& McClelland, 1986) and at 
the Interpersonal model of Lorna Smith Benjamin (1974, 1996, 1999, 2003). He defined Ego state as “...schemas and working models made of constraint networks, typically correlated, that define each specific ego state type. For example there are three types of constraints that involve creativity, normativity and reality analysis and description. In transactional analysis, those correlated networks have been called Child, Parent and Adult" (Scilligo, 2009, p.62).

This theoretical definition allows for an operational definition of Ego states in terms of four different dimensions, coherently with the four dimensions identified by Benjamin: affection, interdependence, developmental and self-other relationship. This definition has been validated by quantitative research. Through a factorial analysis Scilligo (2005) individuated three ego states, Child, Adult and Parent, with specific definitions (Free, Protective, Critic and Rebellious) according to the relevant dimensions.

The complexity of the model offers the possibility of constructing case formulation in clinical practice around it and trainees are trained to recognise the specific Ego state in order to properly interact and to plan treatment.

Trainees are part of a project of research, starting from their first year, contributing to it by filling in questionnaires (ANINT, ESPERO) (a future project, for example, regards validating the hypothesis of changing of the Ego state profile during the four-year training course, through quantitative research).
They also contribute to the research through their clinical practice with the four clients that they see in a brief psychotherapy session. Questionnaires are used also in the intake sessions and the information coming from it is used, combined with qualitative analysis in order to evaluate the possibility of starting therapy and the related treatment plan. At the end of the process the questionnaire helps check change with a quantitative method.

Students are also trained to individuate a specific profile of Ego state for the person, in the interactive process with the client, during the therapeutic session, as an instrument to read each kind of relationship during the training course. In addition, they are trained to combine systematically their clinical experience and the hermeneutic method with the observation of data, to conceptualize their observation and to actively experiment if it fits the specific person, observing data in the process - even through the Ego state activated - to check the validity of the hypothesis.

In synthesis, our perspective of training psychotherapists includes a balance between Learning Styles, the Learning Mode and the Learning Environments. It includes also the construction of a bridge that continuously allows movement from the clinical practice to the research results and vice-versa, so as to consider the uniqueness of each person and the validity of the quantitative approach, in a continuous dance between nomothetic and idiographic conception. In summary, SCTA Ego state's definition is the specific concept that we use as lynchpin of the virtuous circle.

Figure 2: Examples of activities in our training program and related learning modes

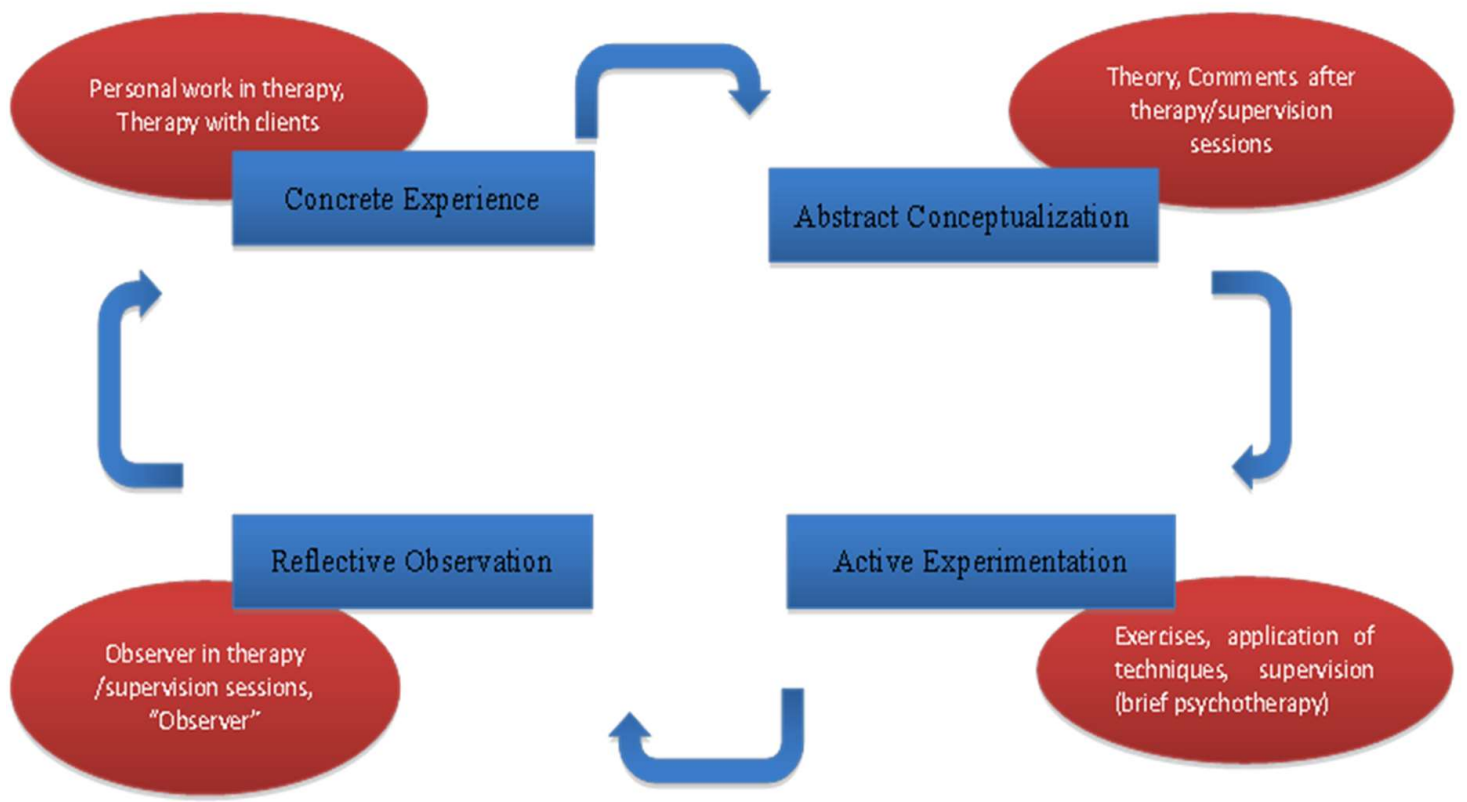




\section{Ethical implications and conclusions}

The complexity of the training model, so strongly intertwined with research, theory and clinical practice, and anchored to the Experiential Learning model of Kolb and Fry underlines the importance of considering the wide and serious task of training for future psychotherapy. They will be the instrument through which suffering people who have lost hope may regain their trust in their possibilities, may open their heart to life again, and increase their well-being and personal, interpersonal and community context. We are aware of the deep responsibility and the need for protection for the therapist, especially the new ones.

We think that this perspective in the training process helps in an ethical way by considering the Learning model, taking care of the preferential styles of each person, contributing to promote respect of the personal way of being of the trainee. In addition, especially considering the group setting, it contributes to increasing the personal view through different learning environments in order to empower the capacity to look at reality and open new perspectives that will help the trainees develop new modalities to be in contact with different people; this means that she commits herself in the relations.

The "objective" perspective is powerfully empowered by the "subjective" one. Our main goal is to combine these two perspectives and to take into consideration the circularity among theory, research, clinical practice and training, so that a psychotherapist can become a scientist for each person they encounter, respecting their uniqueness and becoming curious about the spectacular miracle of change through accurate and well informed guidance.

\section{References}

Andersen, S. M., \& Chen, S. (2002). The relational self: An interpersonal social-cognitive theory. Psychological Review, $109,619-645$

Baldwin, M. W. (1992). Relational schemas and the processing of social information. Psychological Bulletin, 112, 461-484.

Baldwin, M. W. (1994). Primed relational schemas as a source of self-evaluative reactions. Journal of Social and Clinical Psychology, 13, 380-403.

Baldwin, M. W. (1997). Relational schemas as a source of ifthen self inference procedures. Review of General Psychology, 1, 326-335.

Bandura,A. (2002). Autoefficacia: Teoria e Applicazioni. Trento: Erikson

Bandura, A. (2012). Adolescenti e Autoefficacia. II ruolo delle credenze personali nello sviluppo individuale. Trento: Erikson

Benjamin, L.S. (1974). Structural analysis of social behavior (SASB).Psychological Review, 81, 392-425.
Benjamin, L. S. (1996). Interpersonal theory of personality disorders. In J. F. Clarkin and M. F. Lenzenveger (Eds.) Theories of Personality Disorders. New York: Guilford Press.

Benjamin L.S. (1999). Diagnosi interpersonale e trattamento dei disturbi di personalità. Roma: LAS.

Benjamin, L. S. (2000). Intrex user's manual. Salt Lake City: University of Utah.

Benjamin, L. S. (2003). Interpersonal Reconstructive Therapy. Promoting change in non-responders. New York: Guilford Press.

De Luca, M.L., Tosi , M.T. (2012). Social-Cognitive Transactional Analysis : An introdution to Pio Scilligo's model of Ego states. Transactional Analysis Journal, 41, No 3, 206-220.

de Nitto, C. (1991). Strategie e tecniche di intervento terapeutico: uno strumento per la supervisione clinica. Atti del Convegno Nazionale di Analisi Transazionale, Roma: SIAT 1991

de Nitto, C. (2006).(a cura di). L'arte della psicoterapia. Itinerari di formazione alla psicoterapia secondo un'ottica analiticotransazionale "integrata". Roma: LAS.

Erskine, R. (1982). Supervision psychotherapy: Models for Professional Development. Transactional Analysis Journal, 12, 314-321.

Hudson, L. (1966). Contrary imaginations. Middlesex, England: Penguin Books.

Kolb, D. A. (1976). Learning-Style Inventory, Boston, MA: McBer and Company.

Kolb, D. A. (1981). Experiential learning theory and the learning style inventory: A reply to Freedman and Stumpf. Academy of Management Review, 6(2), 289-296.

Kolb, D. A. (1984). Experiential learning: Experience as the source of learning and development, Upper Saddle River, New Jersey: Prentice Hall.

Kolb, D. A., \& Fry, R. E. (1975). Toward an applied theory of experiential learning, In C. Cooper, (Ed), Theories of group processes. London: Wiley

Richmond, A. S., \& Cummings, R. (2005). Implementing Kolb's learning styles into online distance education. International Journal of Technology in Teaching and Learning, 1 (1), 45-54

Rumelhart, D. E., \& McClelland, J. L. (1986). Parallel distributed processing: Explorations in the microstructure of cognition: Vol. 1. Foundations. Cambridge, MA: MIT Press/ Bradford Books.

Scilligo, P. (2000). Il questionario ANINT-A36: uno strumento per misurare la percezione di sé. Psicologia Psicoterapia e Salute, 6, 1-35.

Scilligo, P. (2003). Defining Ego States in relational and developmental terms. EATA Newsletter, n. 79, February 2004 $7-13$

Scilligo, P. (2005). La nuova sinfonia dei molti Sé. Roma: LAS.

Scilligo, P. (2009). Analisi Transazionale Socio Cognitiva. Roma: LAS.

Scilligo, P., and Benjamin, L. S. (1993). L'analisi strutturale del comportamento interpersonale. In Scilligo, P. (a cura di), Sistemi intrapsichici e interpersonali. Roma: IRPIR.

Tosi,M.T., de Nitto, C., Bianchini, S. (2012, in press). A SocialCognitive Definition of Ego States to Implement TA Research. II Conference TA on Research, Luton 